\title{
ANÁLISE DE DISCURSOS INCLUSIVOS EM ESCOLAS DE ENSINO REGULAR A PARTIR DO RELATO DE PROFESSORES E GESTORES
}

\section{Analysis of inclusive discourses in regular education schools from the report of teachers and managers}

Daniel Nascimento Teixeira Oliveira - Universidade Presbiteriana Mackenzie/Brasil Eduardo Fraga de Almeida Prado - Universidade Presbiteriana Mackenzie/Brasil

RESUMO: Esta pesquisa tem como tema a inclusão escolar, sob a perspectiva de sua articulação discursa com outros campos do saber e discursos, buscando refletir sobre as práticas discursivas que possuem status de verdade na contemporaneidade, ao narrar e ser narrada por todos aqueles envolvidos no cotidiano escolar e que permearão o fazer destes. Nesse sentido, propomos investigar e refletir criticamente a partir dos relatos de professores e gestores de escolas de ensino regular sobre suas percepções a respeito dos processos de inclusão, buscando diferentes concepções e campos de tensão em tais práticas. A amostra foi composta por 5 professores e 2 gestores de escolas públicas de ensino regular. As informações foram coletadas por entrevista semi-estruturada a partir de roteiro previamente elaborado. A análise destas foi elaborada pela organização das práticas discursivas em três categorias, quais sejam: como os profissionais entendem o processo de inclusão escolar, como se percebem neste processo e a presença de outros campos do saber. Concluimos que o discurso da educação inclusiva se articula com áreas como a pedagogia, medicina e psicologia no sentido da produção de um sujeito alocado e representado como anormal, fazendo-se necessário para a efetivação da inclusão escolar, práticas discursivas que se fundamentem nas diferenças e heterogeneidade.

Palavras-chave: Discurso. Inclusão Escolar. Práticas.

ABSTRACT: This research has as its theme the school inclusion, from the perspective of its discourse articulation with other fields of knowledge and discourses, seeking to reflect on the discursive practices that have true status in contemporary times, narrating and being narrated by all those involved in daily school life. and that will permeate the making of these. In this sense, we propose to investigate and critically reflect from the reports of teachers and managers of regular schools about their perceptions about the inclusion processes, seeking different conceptions and fields of tension in such practices. The sample consisted of 5 teachers and 2 managers of public schools of regular education. The information was collected by semi-structured interview based on a previously prepared script. The analysis of these was elaborated by the organization of discursive practices in three categories, namely: how professionals understand the process of school inclusion, how they perceive themselves in this process and the presence of other fields of knowledge. We conclude that the inclusive education discourse articulates with areas such as pedagogy, medicine and psychology in the sense of the production of an allocated subject and represented as abnormal, making it necessary for the inclusion of school, discursive practices that are based on differences and heterogeneity.

Keywords: Discourse. Practices. School Inclusion.

Educação, Psicologia e Interfaces, Volume 3, Dossiê Inclusão e Diversidade, p. 37-51, 2019.

ISSN: 2594-5343. DOI: https://doi.org/10.37444/issn-2594-5343.v3i4.175 


\title{
1. INTRODUÇÃO
}

A Inclusão Escolar é um tema um tanto amplo, entendido de diversas maneiras, que nas últimas décadas vem se (re)configurando no Brasil, como um imperativo no contexto escolar e uma urgência social que mobiliza toda a sociedade (RECH; LOPES, 2013). A partir desta perspectiva, o discurso sobre a in/exclusão narra e é narrado por todos aqueles envolvidos no cotidiano escolar gerando interfaces com outros discursos e campos do saber como a Medicina e Psicologia.

O tema desta pesquisa se justifica pela necessária reflexão acerca das práticas discursivas que possuem status de verdade na contemporaneidade, e que vão permear o fazer de diversos campos do saber, sobretudo no contexto escolar. Nesse sentido, é prudente o distanciamento das práticas para que se possa refletir sobre o que as motivam e seus objetivos, como também quais as práticas discursivas que justificam as mesmas.

Analisando a inclusão escolar, a partir de suas continuidades e descontinuidades, é no contexto histórico do século XX que circulam os discursos sobre uma educação para todos, encontrando expressão na Declaração dos Direitos da Criança de 1959 que dispôs:

\begin{abstract}
A criança gozará todos os direitos enunciados nesta Declaração. Todas as crianças, absolutamente sem qualquer exceção, serão credoras destes direitos, sem distinção ou discriminação por motivo de raça, cor, sexo, língua, religião, opinião política ou de outra natureza, origem nacional ou social, riqueza, nascimento ou qualquer outra condição, quer sua ou de sua família (DECLARAÇÃO DOS DIREITOS DA CRIANÇA, 1959, p.1).
\end{abstract}

Este dispositivo foi transformado em lei no Brasil em 1961 através da Lei de Diretrizes e Bases da Educação Nacional, que dispôs a respeito do direito à educação dos "excepcionais" e "preferencialmente dentro do sistema de ensino geral" (SARDAGNA, 2009). Considerando este marco legal, o mesmo encontra consonância com o discurso médico-pedagógico, no qual tais campos do saber se cruzam desde o período imperial brasileiro, em que médicos formados na Europa, atendiam familiares deficientes físicos, e a deficiência era um campo de estudo exclusivamente da medicina. Tal atendimento, que era oferecido em hospitais e asilos, utilizava o regime de internato e a escolarização se dava em espaços anexos às instituições (SILVA, 2016).

De acordo com Jannuzzi (2006), as publicações acerca da deficiência até 1930 eram de autoria principalmente de médicos, e sob influência deste discurso, testemunhamos a emergência, na pedagogia, do discurso da Educação Especial, sendo 
Análise de discursos inclusivos em escolas de ensino regular a partir do relato de professores e gestores

este pautado na reabilitação de caráter eminentemente disciplinar e adaptacionista a partir de uma compreensão do fenômeno da deficiência como condição individual e orgânica. A partir de tal lógica, são criadas as escolas e classes especiais, em que o aluno que é narrado como sendo alvo de "atenção especial" devido ao seu "atraso considerável quanto à idade regular de matrícula", receberá a atenção que se compreendia necessária diante de suas especificidades (SARDAGNA, 2009). Isto posto, serão nestas instituições que o aluno será normalizado e vigiado de maneira mais eficaz e, através da comparação com os demais, se estabelecerá uma média enquanto dispositivo da norma e, a partir desta, os corpos serão distribuídos, classificados e hierarquizados na instituição enquanto equipamento que dá suporte ao disposto na lei de 1961 (FOUCAULT, 2004).

Tais práticas discursivas, deram corpo ao que se estabeleceu no final do século XX e começo do século XXI como Educação Inclusiva que, por sua vez, convocou todos indivíduos da sociedade a se responsabilizarem pela educação para todos, de acordo com o decreto $\mathrm{N}^{\mathrm{o}} 6.094$ de 2007.

O referido decreto em seu terceiro capítulo intitulado "Da adesão ao compromisso", em seu sétimo artigo convida os entes públicos e privados, além da família, organizações da sociedade civil, pessoas físicas e jurídicas, entre outros, a se mobilizarem por educação básica. O presente modelo possui descontinuidades em relação à Educação Especial, como, por exemplo, naquilo que se refere à classe especial para o indivíduo anormal, uma vez que esta é descartada e passa a ser utilizada apenas como alternativa educacional quando o aluno não puder ter acesso ao conteúdo da sala comum.

Malgrado o contraste entre os modelos, o que ainda rege a Educação Inclusiva é a noção de normalização dos corpos que, desta vez, vai se basear nos moldes disciplinares, homogeneizando o espaço e as pessoas, trazendo a todos para "perto" (SARDAGNA, 2009). Neste sentido, as políticas de inclusão vão se ocupar não mais do sujeito anormal, mas sim com a massa viva da população, controlando, modificando e estabelecendo o que é desejável ou não. Trata-se, de fato, do desenvolvimento de uma biopolítica e de estratégias de governamentalização, isto é, trata-se de um modo de gerir as deficiências e dificuldades de aprendizagem valendo-se da articulação com diferentes saberes-poderes e práticas, como por exemplo, as da Medicina e Psicologia (LOPES et al. 2010).

Educação, Psicologia e Interfaces, Volume 3, Dossiê Inclusão e Diversidade, p. 37-51, 2019. ISSN: 2594-5343. DOI: https://doi.org/10.37444/issn-2594-5343.v3i4.175 
A partir da apresentação de como se transformaram os processos inclusivos até a contemporaneidade, neste momento, é mister destacar alguns operadores conceituais da obra de Michel Foucault que nortearam o desenvolvimento desta pesquisa.

Michel Foucault, em determinado momento de sua obra, dirige seus estudos para aquilo que emerge no século XVIII sob a forma de saberes e práticas, em um processo de individualização e ao mesmo tempo homogeneização dos indivíduos através da disciplina e vigilância, que têm por objeto concreto o corpo, tanto individualmente (biopoder) como da população enquanto corpo vivo (biopolítica) (PORTOCARRERO, 2004). Neste sentido a obra foucaultiana vai tratar das relações de saber-poder (VEIGA-NETO, 2007), não apenas do ponto de vista macrofísico como nas relações entre o Estado e a população, mas também sob a ótica da microfísica, do poder capilar, das relações de poder que se fazem presentes em instituições como a escola, família, prisões, etc.

Percorrendo a analítica do poder, durante o século XVIII emerge uma forma de poder que atua em conjunto com o poder disciplinar em nível dos corpos dos indivíduos e que vai entender o corpo do sujeito enquanto ser biológico. Ao contrário do poder soberano que era um poder de morte do rei sobre seus súditos, trata-se agora de um poder de 'fazer viver', de um poder que não apenas coage mas principalmente produz modos de subjetivação. Tal poder foi denominado pelo autor como biopoder (CASTRO, 2016).

Cabe destacar que emerge também no mesmo século um tipo de relações de poder sobre a população, que não têm como finalidade o corpo dos sujeitos individualmente, e sim o "corpo vivo com uma multiplicidade de cabeças", isto é, a população. Trata-se aqui da biopolítica, que tem por campo de abrangência a população, enquanto espécie humana, e vai categorizar a partir de suas estatísticas, demografia e medicina sanitária por exemplo, esse corpo vivo, e então pensar em ações para controlar e prever seus riscos, dito de outro modo, trata-se de estratégias de gestão da população (VEIGA-NETO, 2007).

Biopoder e biopolítica devem ser compreendidos como dois mecanismos complementares, um em nível do corpo que tem como base mecanismos disciplinares, e outro em nível de população atuando através dos mecanismos regulamentadores, e será justamente a norma que unirá as dimensões individual e coletiva. É através da norma que se comparam as características individuais e cada uma em relação ao conjunto, não havendo espaço para não normatividade, uma vez que o desviante é um caso da norma, 
Análise de discursos inclusivos em escolas de ensino regular a partir do relato de professores e gestores

portanto não existe doença ou saúde em si, senão em relação a uma capacidade normativa (VEIGA-NETO, 2007).

É no cruzamento dos estudos foucaultianos e no desenvolvimento da temática da Inclusão Escolar apresentados até aqui, que se encontra o escopo desta pesquisa. Entendendo a escolarização como um imperativo contemporâneo, a escola se torna, assim como outras instituições, um lugar onde se opera a norma, através da intersecção com os saberes-poderes socialmente legitimados a instituir práticas discursivas a respeito da anormalidade, como, por exemplo a Medicina e a Psicologia (RAMOS, 2014).

Partindo do dispositivo da média que estabelece uma regra da aprendizagem normal e anormal, se produz o que Foucault vai chamar de "indivíduo a ser corrigido" (DAL'IGNA, 2013), e, neste sentido, uma prática inclusiva acrítica pode ser a porta de entrada para a criação de estratégias de homogeneização de individualidades através da norma e, assim, agir sobre uma população de maneira a aproximá-la de um tipo ideal (RAMOS, 2014).

Diante do exposto, entendemos que as narrativas de professores e gestores a respeito destes alunos trazem consigo suas perspectivas e compreensões a respeito da Educação Inclusiva e, por conseguinte, orientam suas práticas (MOHR; POSSA; NAUJORKS, 2014). Cabe reiterar que é na relação do saber pedagógico com outros campos do saber, como as já referidas Medicina e a Psicologia, que estes alunos são categorizados e se desenvolvem as estratégias educacionais para lidar com esta população (RAMOS, 2014). É justamente neste ponto que esta pesquisa, tendo em vista a base teórica apresentada, refletiu sobre como as relações escolares se constituem no que diz respeito à Inclusão Escolar, da criança previamente diagnosticada ou não.

O objetivo geral residiu em analisar a partir do referencial teórico proposto e material coletado, as forças, relações de poder e jogos de verdade que constituem e atravessam as práticas inclusivas presentes em escolas de ensino regular, a partir das narrativas de professores, coordenadores e diretores presentes neste contexto.

Os objetivos específicos consistuíram em refletir criticamente a respeito das possibilidades de inclusão nas escolas participantes da pesquisa, investigando se há diferentes concepções em relação ao processo de inclusão escolar entre equipe gestora e professores e possíveis tensões a partir destas práticas discursivas. 
Vale destacar que não nos encontramos isolados em nossa tentativa de reflexão. Ao elaborarmos uma busca nas principais bases de dados, a partir dos descritores "Inclusão escolar" e "Foucault", notamos que no período de 2013 a 2018, muito se refletiu a respeito deste tema. Grosso modo, a produção acadêmica converge para uma análise crítica sobre os processos de inclusão escolar. Dentre as diferentes abordagens à temática, podemos ressaltar as que relacionam a Inclusão Escolar com o neoliberalismo como Pagni (2017), Henning e Silva (2014), Naujorks e Possa (2013) e Machado (2015), assim como os que tratam os processos inclusivos enquanto práticas de governamentalidade como Cardoso (2013), Ramos (2014), Sobrinho (2015) e Carvalho (2015); destacam-se também os artigos que abordam a inclusão sob a ótica da normalização como em Garré e Rosa (2017), Graff e Medeiros (2016), Pagni (2015), Lockmann (2013) e, por fim, artigos que dialogam a inclusão escolar com outras áreas do saber como Monteiro (2014), Granata, Hillesheim, Cappellari e Couto (2017) e Dametto e Esquinsani (2014).

\section{MATERIAL E MÉTODO}

Trata-se de pesquisa de caráter exploratório e qualitativo, sendo esta compreendida como a pesquisa cujos objetivos residem mais em aprofundar no mundo dos significados dos participantes da pesquisa do que na possibilidade de generalizações de suas narrativas (MINAYO, 1993).

Com o objetivo de se aproximar do processo de produção de significados dos participantes, foram entrevistados cinco professores e dois coordenadores ou diretores de escolas públicas do estado de São Paulo.

A seleção da amostra se justifica pelas posições que esses profissionais ocupam na escola pública, na medida em que entendemos que professores têm atuação mais próxima aos alunos e das práticas pedagógicas propriamente ditas; já os coordenadores e diretores, por sua vez, ocupam cargos de gestão da escola, lidando com os alunos de maneira indireta. Delimitando as diferenças na atuação dos profissionais, buscamos as possíveis ressonâncias e dissonâncias das práticas discursivas destes profissionais a respeito da temática da Inclusão Escolar.

Enquanto instrumento de coleta das informações, utilizamos entrevistas semiestruturadas, sendo estas compreendidas como decorrentes de um roteiro previamente estruturado que traz consigo os aspectos considerados indispensáveis para 
Análise de discursos inclusivos em escolas de ensino regular a partir do relato de professores e gestores

uma efetiva aproximação do problema de pesquisa, a saber: a compreensão de professores, coordenadores e/ou diretores sobre o processo de inclusão escolar.

Cabe ressaltar que a prévia elaboração do roteiro não possui a finalidade de restringir a construção do campo da entrevista na medida em que este deverá ser tributário do processo de mútua afetação entre entrevistador e entrevistado. Dito de outro modo, caberá ao entrevistador seguir o fluxo de associações do entrevistado pois estes podem constituir importantes elementos a respeito do problema de pesquisa (BLEGER, 2007).

Entramos em contato com as escolas através da carta de informação da pesquisa, que explicita os procedimentos, os pressupostos teóricos e os objetivos desta, assim como os respectivos termos de consentimento e aspectos éticos implicados durante todos os procedimentos desta. As entrevistas, foram realizadas nas escolas e áudio gravadas para transcrição fidedigna e posterior análise, reiterando aos colaboradores os procedimentos éticos de realização da pesquisa, especialmente naquilo que toca à garantia do sigilo.

Os riscos envolvidos no desenvolvimento da pesquisa foram mínimos, contudo, considerando a metodologia da pesquisa, o participante poderia sentir-se discriminado ou estigmatizado a partir do conteúdo revelado, no entanto, no caso de qualquer desconforto a entrevista seria imediatamente interrompida sem qualquer ônus ao participante cabendo ao pesquisador efetuar todos os procedimentos necessários para sanar o mal-estar decorrente da elaboração da entrevista, garantindo local reservado e liberdade para não responder à questões constrangedoras. Os benefícios residiram em promover aos participantes, sejam professores ou gestores de escolas de ensino regular, reflexões críticas sobre as práticas inclusivas e, decorrente destas, a possível produção de novas práticas e estratégias de intervenção.

Os procedimentos para análise das informações coletadas foram efetuados de acordo com a análise de conteúdo proposta por Bardin (2011). De acordo com os ensinamentos da autora, trata-se de processo que consiste em três etapas, a pré-análise, a exploração do material e o tratamento dos resultados.

I- Pré-Análise: Essa fase possui três objetivos que não obedecem a uma ordem cronológica e estão estreitamente ligados, são eles: a escolha dos documentos que serão analisados, a formulação das hipóteses e dos objetivos e a elaboração de indicadores que fundamentam a interpretação final (BARDIN, 2011). Essa pesquisa tratou como documento e alvo de análise, as transcrições das falas dos entrevistados, com o objetivo 
de encontrar nestas falas, os possíveis atravessamentos do discurso da Educação inclusiva por áreas do saber.

II - Exploração do Material: Aqui se trata da análise propriamente dita, ou seja, de um processo mecânico de operações de codificação, desconto ou enumeração, com a função de transformar os dados brutos do texto em uma representação do conteúdo (BARDIN, 2011). Trata-se, portanto, da transcrição do material gravado nas entrevistas, das repetidas leituras desse material e do levantamento das partes relevantes à temática.

III - Tratamento dos Resultados e Interpretação: os resultados são condensados e as informações fornecidas pela análise colocadas em relevo, no sentido de se verificar os conteúdos que mais aparecem, assim como os que destoam, possibilitando propor interpretações e inferências (BARDIN, 2011). A partir do estabelecimento de categorias de análise, as comparamos, procurando nessas divisões o que aparece de comum daquilo que é destoante, separando o que é significativo do que não, possibilitando assim, interpretações acerca da análise.

\section{RESULTADOS E DISCUSSÃO}

Foram levantadas e analisadas categorias a partir dos dados coletados e do referencial teórico e método anteriormente expostos. A primeira categoria diz respeito a como os profissionais escolares entendem o processo de inclusão escolar.

Os professores de ensino regular, retrataram o processo de inclusão escolar, de maneira geral, por meio das dificuldades que encontram no desenvolver do mesmo. A falta de formação dos professores, é apontada pela maioria como o maior empecilho para elaborar práticas educacionais que sejam adequadas no atendimento de crianças com alguma particularidade, o que gera, no entender dos entrevistados, práticas que acabam por promover exclusão. Tal defasagem é apontada como produto de uma formação que não contemplou a temática da inclusão, desinteresse por parte dos professores na temática e descaso do Estado em relação a efetividade do processo de inclusão. Tais concepções se alinham aos relatos dos gestores, que ao dissertar sobre a mesma questão, argumentaram sobre os empecilhos do processo de inclusão, sobretudo das dificuldades advindas da má formação dos professores e de sua falta de interesse em formação. As concordâncias são ilustradas em dois excertos: 
Análise de discursos inclusivos em escolas de ensino regular a partir do relato de professores e gestores

[...] na faculdade a gente não foi preparado para isso, então a gente foi trabalhar sem isso no estado, então quando começou a inclusão no estado foi muito jogado eu acho que deveria ter tido todo um preparo, quer fazer inclusão? É bom, é ótimo, mas eu acho que deveria haver salas especializadas sim porque as salas hoje em dia são superlotadas [...] (Professor 3).

[...] dependendo da síndrome que esse aluno apresente, a gente não sabe como lidar, então o que acontece, você vai sempre deixando de lado, não é? Então você colocar um aluno com uma certa deficiência dentro de uma sala com quarenta alunos, é difícil um professor que não tem habilidade para aquilo, saber como lidar com essas diferenças [...] (Gestor 2).

No que pese as concordâncias entre professores e gestores, houve dissonâncias quanto a formação e possibilidades de inclusão dos alunos. Enquanto professores entendem que o convívio social em salas regulares em conjunto com o acompanhamento especializado, são preponderantes para a efetividade da inclusão escolar, os gestores abordaram a questão partindo das limitações impostas pelas deficiências e síndromes, bem como da importância do acompanhamento especializado conforme o diagnóstico dos alunos.

Nesta primeira categoria, é possível refletir a partir das várias menções a má formação ou pouca familiaridade dos professores com a temática da inclusão escolar. Considerando a aprendizagem dos alunos como finalidade do processo de ensino por parte dos professores, as intervenções são de ordem pedagógica e produzidas através das trocas entre os demais professores e o saber que lhes submete enquanto profissionais, portanto, as queixas sobre falta de informação sobre deficiências e síndromes apontadas anteriormente, evidenciam a cultura terapêutica e homogeneizante presente na Educação Especial tendo por objetivo produzir o saber daquele determinado sujeito estabelecendo um paralelo com a norma (WEDMAN, 2014). A dissonância entre professores e gestores sobre os limites da inclusão escolar, corrobora com a diferenciação entre estratégias pedagógicas construídas a partir da troca entre profissionais e de sua experimentação com todos os alunos, de uma cultura terapêutica e preocupada com o diagnóstico ainda presente no ambiente escolar.

A segunda categoria é constituída pela compreensão dos profissionais escolares sobre a percepção que possuem no que toca à inclusão escolar. Neste sentido, as falas dos professores convergem para o trabalho mútuo dos profissionais, apesar de relatarem o processo de inclusão como imposto, a sua revelia, pelo Estado, seja com orientações de 
estudo e cursos ou compartilhando práticas exitosas. Em relação a gestão da escola, as reuniões em forma de aula de trabalho pedagógico coletivo (ATPC) são narrados como momentos de trocas importantes entre os profissionais, muitas vezes através de palestras dos professores que têm mais familiaridade com o processo de inclusão. Os gestores, por sua vez, acompanham os professores ao falarem principalmente da disposição de alguns deles em aprender sobre a temática da inclusão, bem como da importância das reuniões de ATPC em que também consideram que ocorrem trocas importantes. Para elucidar as convergências apresentamos alguns trechos.

[...] eles cobram "Você tem que ensinar porque veio da diretoria de ensino e vão cobrar da gente", só que ai eles começaram a dar esse apoio no sentido da $\mathrm{V}$. que era professora que trabalhava com esses alunos, ela também sempre fazia no ATPC tipo uma "palestrinha" (sic) né e ai mostrava a diferença de síndromes e tudo mais [...] (Professor 2).

[...] nas reuniões de ATPC a gente comenta com os professores, de modo geral, como que está esse aluno e como esse professor pode estar trabalhando na sala de aula para poder sanar um pouquinho dessa dificuldade que ele vai ter [...] (Gestor 1).

Em contraponto a tais concepções, houve falas de professores que não se alinharam a dos gestores, enquanto os primeiros focaram na abertura para aprender uns com os outros e da preocupação em não reproduzir práticas excludentes e preconceituosas, os segundos disseram ter a percepção um tanto rasa sobre o processo de inclusão por não acompanharem os alunos de maneira mais próxima como os professores.

Naquilo que toca a categoria apresentada anteriormente, os professores ao serem qualificados pelos discursos da inclusão escolar, de forma positiva ou negativa enquanto mais ou menos inclusivos, assumem uma posição de assujeitamento, sendo esta uma relação de poder que lhes é exterior, mas que também, justamente pelo fato de constituílos, faz parte daquilo que eles mesmos vão se tornando ao nortearem suas práticas sob a égide da inclusão (MOHR; POSSA; NAUJORKS, 2014), nesse sentido, a troca entre os professores através do compartilhamento de práticas, modos de agir, e de se exercer a docência tidas como positivas e exemplares, subjetivam e operam sobre os modos de ser professor sob uma perspectiva inclusiva. Ainda sobre as dissonâncias entre gestores e professores, as práticas discursivas que promovem subjetivação, o fazem também através da vigilância e controle fazendo com que os profissionais escolares busquem ser mais adequados e politicamente corretos em relação aos outros e ao fazer, justificam-se as falas sobre o medo de soar contrário a inclusão escolar e preconceituoso. 
Análise de discursos inclusivos em escolas de ensino regular a partir do relato de professores e gestores

A terceira categoria levantada versa sobre como a presença de campos do saber, para além da Pedagogia, bem como a presença do laudo, é percebida pelos profissionais escolares. Para tal, os professores disseram que não percebem profissionais de outras áreas no processo de inclusão, exceto cuidadores e intérpretes de libras que atuam dentro da escola acompanhando os alunos. Entretanto, há uma similaridade presente nas falas dos professores ao mencionarem médicos e psicólogos sempre fazendo referência ao laudo diagnóstico, haja vista que tal documento possibilitaria o início do processo de inclusão. Em consonância ao apresentado anteriormente, os gestores disseram não perceber outras áreas do saber no processo de inclusão, apesar de também reconheceram a impotância do laudo diagnóstico. Contudo, professores e gestores apresentaram algumas discordâncias em seus relatos, os segundos apontaram que é comum encaminhar um aluno para serviços de saúde próximos da escola, porém, apontam a família como principal entrave para constatação do diagnóstico e obtenção do laudo, uma vez que muitos apresentam receio do filho possuir alguma patologia; já os professores, por seu turno, apesar de reconhecerem a importância do laudo, relatam preocupação com o possível estigma negativo sobre o aluno diagnosticado.

Em relação a terceira categoria, a análise se constitui ao entender que a importância do laudo diagnóstico retratada pelos profissionais da escola, atesta a presença do poder médico dentro da escola (RAMOS, 2014). A intenção de conhecer, capturar e governamentalizar sujeitos que fogem a um padrão de normalidade inventado, chancela a parceria entre pedagogia e outros campos do saber, sobretudo a medicina, como expresso na fala de um professor e um gestor.

[...] quando o aluno vem laudado com a deficiência, a professora vem com a especificação da doença e tudo, aonde [sic] a pessoa específica da área desenvolve um trabalho baseado em cima daquela deficiência que o aluno tem (Professor 5).

[...] você começa a perceber e fala 'olha, passa no pediatra, pede um encaminhamento pro neuro' [sic] né, por quê? Porque a gente acredita que, talvez para alguns, é o que vai diagnosticar com mais clareza, diferente do psiquiatra e do psicólogo, que também identifica, mas aí são síndromes diferentes, as vezes ele passa no 'neuro' aí o 'neuro' pede exames só que não dá nada, aí ele passa em um psiquiatra ou num psicólogo, aí ele descobre lá alguma coisa mais emocional do que propriamente neurológico, então acho que a importância é muito grande (Gestor 1).

Educação, Psicologia e Interfaces, Volume 3, Dossiê Inclusão e Diversidade, p. 37-51, 2019. ISSN: 2594-5343. DOI: https://doi.org/10.37444/issn-2594-5343.v3i4.175 
A produção de saber sobre os sujeitos anormais, através das descrições e classificações que marcam o processo de inclusão escolar, acabam por produzir verdades, nesse sentido, a preocupação dos professores em relação ao estigma desses alunos faz bastante sentido uma vez que lidam mais proximamente com eles; já em relação aos gestores, todos os atores da educação são responsabilizados pelo imperativo da escola inclusiva, inclusive a família, portanto sua convocação a participar do processo enquanto estratégia de governo (RAMOS, 2014).

\section{CONSIDERAÇÕES FINAIS}

Por meio deste trabalho, pareceu-nos possível analisar, considerando os jogos de forças e relações de poder que narram e são narrados pelos profissionais escolares participantes da pesquisa, que o discurso da educação inclusiva, se constitui através da articulação de áreas como a pedagogia e a medicina, produzindo um sujeito alocado como anormal, que emerge por meio de descrições e classificações no sentido da produção de um saber. Portanto, a inclusão escolar parece ser considerada somente partindo do campo de tensão que abarca os conceitos de in/exclusão.

No que pesem as articulações discursivas que compõem a educação inclusiva, houve dissonâncias importantes entre os enunciados emitidos por professores e gestores nas categorias analisadas. As práticas discursivas que permeiam as concepções dos gestores das escolas parecem estar mais distantes do campo em que elas ocorrem do que em relação aos professores, o que proporcionou entender quais jogos de poder são mais presentes dependendo de como o ator é chamado a participar do processo de inclusão.

Portanto, pensar a inclusão escolar enquanto possibilidade de transformação social, requer que seja discutido, sobretudo, o papel da escola na sociedade. Uma vez que a educação inclusiva deveria ser estruturada em virtude das necessidades dos alunos, não basta garantir o acesso, mas também devem ser garantidas as condições de permanência nos diversos níveis de ensino, considerando as múltiplas diferenças e buscando atender as necessidades do processo de aprendizagem de cada aluno. Tal percepção sobre a escola demanda repensar o valor de verdade do discurso médico presente na sociedade, discurso este que é reproduzido no âmbito escolar através do laudo diagnóstico, produzindo práticas embasadas sob a perspectiva da incapacidade, do enrijecimento das alternativas pedagógicas e da doença. Diante do exposto, seria interessante que as transformações 
Análise de discursos inclusivos em escolas de ensino regular a partir do relato de professores e gestores

contemplassem a formação dos profissionais escolares que abordem aspectos políticos, culturais e sociológicos do processo de inclusão, valorizando as diferenças e proporcionando um espaço heterogêneo.

Uma vez que a pesquisa qualitativa tem como objetivo aprofundar o campo dos significados dos participantes, este trabalho apresenta limitações quanto ao número de participantes, considerando o número de gestores, bem como a variabilidade da amostra uma vez que foi realizado com alguns membros de uma determinada instituição de ensino. Neste sentido, os resultados ora encontrados não são passíveis de generalização.

Considerando que este trabalho não teve a pretensão de esgotar a temática, mas de contribuir com algumas reflexões, há espaço para outros estudos e sequência nas discussões aqui levantadas, a saber, como os desdobramentos do pensamento foucaultiano nos auxiliam a refletir sobre as práticas inclusivas.

\section{REFERÊNCIAS BIBLIOGRÁFICAS}

BARDIN, Laurence. Análise de Conteúdo. Tradução Luis Antero Reto, Augusto Pinheiro. São Paulo: Edições 70, 2011.

BLEGER, José. Temas da Psicologia: entrevista e grupos; Tradução: Rita Maria M. de Moraes - $3^{\mathrm{a}}$ edição - São Paulo; Martins Fontes, 2007.

CASTRO, Edgardo. Vocabulário de Foucault. Autêntica Editora, Edição: 2, Mês/Ano de publicação: 03/2016.

DAL'IGNA, Maria Cláudia. A invenção da criança normal: conhecimento, desenvolvimento e aprendizagem. In: Inclusão e biopolítica - $1^{\text {a }}$ Edição. Editora Autêntica, 2013.

FOUCAULT, Michel. O cuidado com a verdade. In.: Ditos e escritos V. Ética, sexualidade, política, 2004.

JANNUZZI, Gilberta Sampaio de Martino. A educação do deficiente no Brasil: dos primórdios ao início do século XXI. 2. ed. Campinas: Autores Associados, 2006.

LOPES, Maura Corcini; RECH, Tatiana Luiza. Inclusão, biopolítica e educação.

Educação. (Porto Alegre, impresso), v. 36, n. 2, p. 210-219, maio/ago. 2013.

Disponível em < https://www.redalyc.org/pdf/848/84827901009.pdf> Acessado em 16 fev. 2018.

LOPES, Marua Corcini et al. Inclusão e Biopolítica. Caderno IHU Ideias, ano 8, $\mathrm{n}^{\circ}$ 144, 2010, ISSN 1679-0316.

Educação, Psicologia e Interfaces, Volume 3, Dossiê Inclusão e Diversidade, p. 37-51, 2019. ISSN: 2594-5343. DOI: https://doi.org/10.37444/issn-2594-5343.v3i4.175 
MINAYO, Maria Cecília. O desafio da pesquisa social. In: DESLANDES, Suely Ferreira et al. (Orgs) Pesquisa Social: teoria, método e criatividade. $34^{\mathrm{a}}$ edição, Petrópolis: Editora Vozes, 1993, páginas 9-30.

MOHR, Alana Cláudia; POSSA, Leandra Bôer; NAUJORKS, Maria Inês. Estratégias discursivas de subjetivação docente em tempos de inclusão escolar. X ANPED SUL, 2014. Disponível em <http://xanpedsul.faed.udesc.br/arq_pdf/296-0.pdf> Acessado em 15 fev. 2018.

ONU. Declaração Universal dos Direitos das Crianças. Disponível em <http://www.direitoshumanos.usp.br/index.php/Crian\%C3\%A7a/declaracao-dosdireitos-da-crianca.html>. Acesso em 13 fev. 2018.

PORTOCARRERO, Vera. Instituição escolar e normalização em Foucault e Canguilhem. Revista Educação e Realidade, V. 29, No 1, 2004. Disponível em < https://seer.ufrgs.br/educacaoerealidade/article/view/25424>. Acessado em 19 fev. 2018.

RAMOS, Carolina Lehnemann. O "laudo" na inclusão de alunos no ensino regular: uma estratégia da governamentalidade biopolítica. X ANPED SUL, 2014. Disponível em < http://xanpedsul.faed.udesc.br/arq_pdf/1947-0.pdf> Acessado em 20 jan. 2018)

SARDAGNA, Helena Venites. Da institucionalização do anormal à inclusão escolar. In: FABRIS, Eli Terezinha Heen; KLEIN, Rejane Ramos. In: Inclusão e biopolítica - $1^{\text {a }}$ Edição. 2009. Editora Autêntica 226 ISBN 9788582171417.

SILVA, Kelly Cristina Brandão da. O discurso médico-psicológico na configuração do campo da Educação Especial. Revista Eletrônica de Educação. v. 10, n. 1, p. 69-87, 2016 Artigo ISSN 1982-7199. Disponível em <http://dx.doi.org/10.14244/198271991198>. Acessado em 18 fev. 2018.

VEIGA-NETO, Alfredo. Foucault \& a educação. $2^{\text {a }}$ edição, Belo Horizonte: editora Autêntica, 2007.

WEDMAN, Denise da Rosa. Processo de inclusão escolar no ensino regular: concepções docentes. X ANPED SUL, 2014. Disponível em <http://xanpedsul.faed.udesc.br/arq_pdf/1399-0.pdf> Acessado em 15 fev. 2018.

\section{Credenciais da/os autora/es}

OLIVEIRA, Daniel Nascimento Teixeira. Universidade Presbiteriana Mackenzie/Brasil E-mail: danielnto94@gmail.com

PRADO, Eduardo Fraga de Almeida. Graduado em Direito e Psicologia, tem formação em Psicanálise pelo CEP e formação em Psicanálise com Crianças pelo Instituto Sedes Sapientiae. Especialista em Psicologia Clínica pelo CRP-SP, em Teoria Psicanalítica pela PUC-SP e em Dependência Química pela USP. Mestre e doutor em Psicologia Clínica pela PUC-SP. Professor do Curso de Psicologia da Universidade Presbiteriana. E-mail: eduardo.prado@mackenzie.br 
Análise de discursos inclusivos em escolas de ensino regular a partir do relato de professores e gestores

Endereço para correspondência: Daniel Nascimento Teixeira Oliveira. E-mail:

danielnto94@gmail.com

Como citar este artigo (Formato ABNT): OLIVEIRA, Daniel Nascimento Teixeira; PRADO, Eduardo Fraga de Almeida. Análise de discursos inclusivos em escolas de ensino regular a partir do relato de professores e gestores. Educação, Psicologia e Interfaces, Volume 3, Dossiê Inclusão e Diversidade, p. 37-51, 2019. DOI: https://doi.org/10.37444/issn-2594-5343.v3i4.175

Recebido: 07/08/2019.

Aceito: 20/11/2019.

Educação, Psicologia e Interfaces, Volume 3, Dossiê Inclusão e Diversidade, p. 37-51, 2019. ISSN: 2594-5343. DOI: https://doi.org/10.37444/issn-2594-5343.v3i4.175 